\title{
Influence of Material Properties on Automobile Energy-Absorbing Components Crashworthiness
}

\author{
Liuyan Jie ${ }^{*}, 1,2$ and Ding $\operatorname{Lin}^{1,2}$ \\ ${ }^{1}$ College of Civil Engineering, Heilongjiang University, Harbin 150086, P.R. China \\ ${ }^{2}$ Northeast Frost Civil Engineering Key Laboratory of Heilongjiang University, Harbin 150086, P.R. China
}

\begin{abstract}
In the present work, the simulation analysis of automobile energy-absorbing components was carried out using Finite Element (FE) method. The numerical simulations were carried out using the software LS-DYNA. Automobile energy-absorbing components usually were made of a metal thin walled tube. In the paper, several types of material properties were studied and compared. Results show that the material properties have influence to automobile energy absorbing components crashworthiness.
\end{abstract}

Keywords: Energy-absorbing components, finite element analysis, material properties, strain rate, yield strength.

\section{INTRODUCTION}

In cities traffic jam, automotive accident often occurs to low-speed and behind or angle collisions. No attention is paid to the low speed crashed for no personnel injury [1]. Therefore, it is quite necessary to study the technical problems of the car involved in low velocity impact.

In low velocity impact accident, the automobile energyabsorbing component is expected to be collapsed with absorbing crash energy prior to other body parts so that the damage of the main cabin frame is minimized and passengers may be saved [2].

The automobile energy-absorbing component equipped at the front end of car (see Fig. 1), is one of the most important automotive parts for crash energy absorption.

In the present work, the automobile energy-absorbing component (a kind of thin walled metal tube ) at lowvelocity impact was studied [3, 4], and material properties on automobile energy -absorbing components crashworthiness were proposed.

\section{FINITE ELEMENT MODEL}

\subsection{Model Building}

In case of frontal low-speed collision, the automobile energy-absorbing component absorbs impact energy and reduces the peak load of the impact mainly by the plastic deformation [5,6]. The automobile energy- absorbing component comprises a front longitudinal beam, a bumper beam, a crash- box and front and rear flange. The crash- box plays a key role in low-speed collisions, and the structure is given in Fig. (2).

In this paper, crash-box was made of thin walled tubes, and a finite element model was developed using the software Hypermesh [7]. The axial low velocity impact of the square cross-section tube $(70 \mathrm{~mm}$ width, $140 \mathrm{~mm}$ long and $1.65 \mathrm{~mm}$ thick) is studied firstly. The tube finite element mesh is illustrated in Fig. (3). A rigid plate of $1000 \mathrm{~kg}$, placed on the top of the tube as shown in Fig. (3), axially impacted at the velocity of $4.44 \mathrm{~m} / \mathrm{h}$.

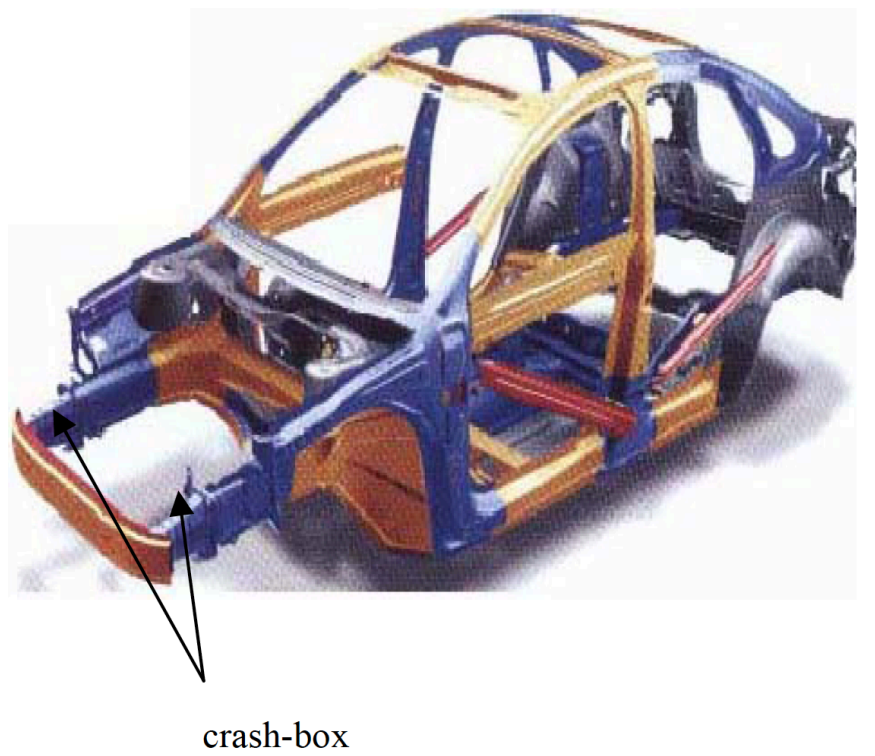

Fig. (1). Position of crash-box in the bodywork.

\subsection{Main Crashworthiness Evaluation Parameters}

In low-speed collision simulation, the most important crashworthiness evaluation parameters of the crash- box are the total impact energy absorption via plastic deformation 
$E s$, the peak impact force $F p$, the compressed displacement of the tube $\delta_{e}$, and the average impact load $F m$. The average impact force $\mathrm{Fm}$ is given by equation (1),

$F_{m}=\frac{E_{s}}{\delta_{e}}$

where $F m$ is arithmetic average value, with $F m$ increasing, the absorbing energy of the tube will be increased. The greater the $\mathrm{Fm}$, the more energy is absorbed, and the better the crew safety. Therefore, in precondition of not more than the permission peak value, the bigger the average impact load is, the better the absorption performance is, and the shorter the compressed displacement is, the better the absorption performance is [8].

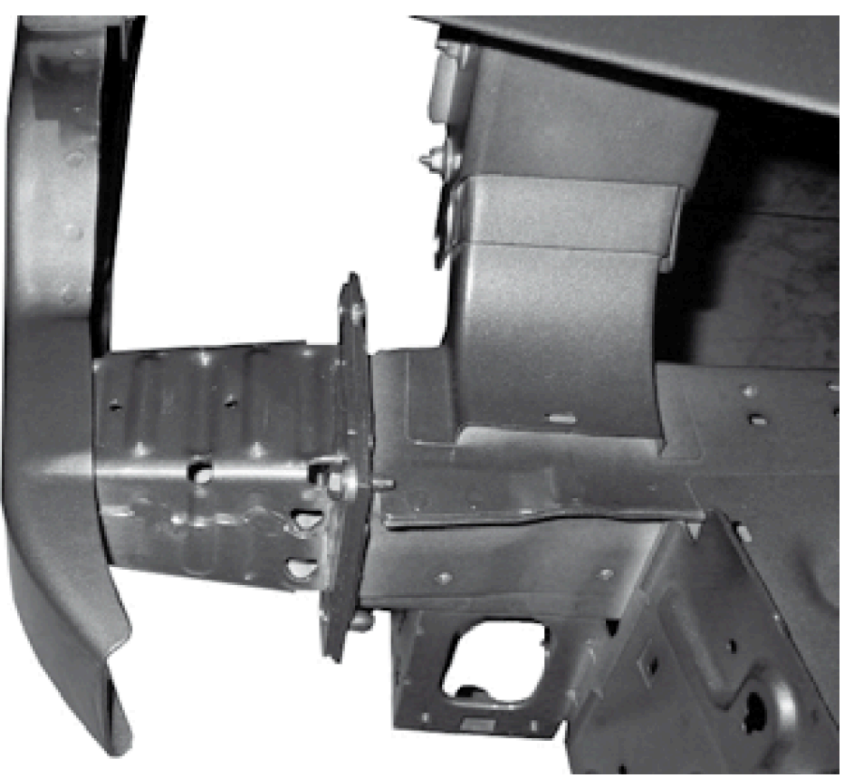

Fig. (2). Structure of crash-box.

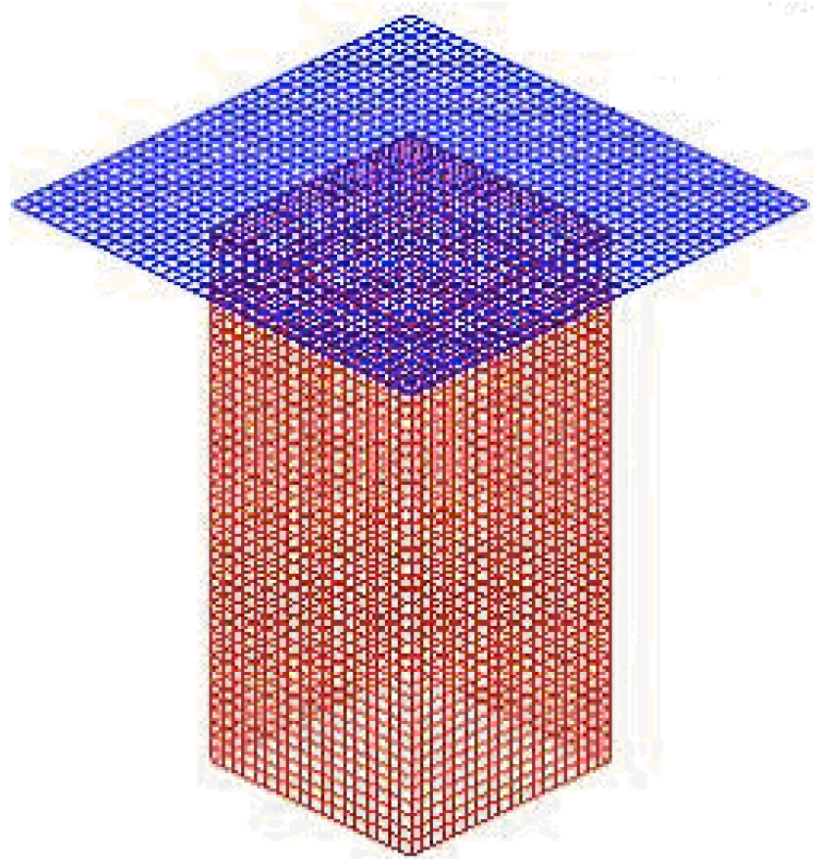

Fig. (3). Mesh model of the tube.

\section{MAIN INFLUENCING FACTORS TO CRASH- WORTHINESS}

There are many factors that can influence crashworthiness characteristics of crash-box in collision simulation process, including crash-box shape, wall thickness, material and so on, in which material properties have great effects on device characteristics. In this paper, influence of material properties to crash-box is chiefly researched.

\subsection{Material Strain Rate}

Vehicle crash simulation, the effect of strain rate to automobile crashworthiness cannot be ignored.

The energy absorption character of the square crosssection tube on axial low velocity impact is simulated by LSDYNA. The tube finite element mesh is illustrated in Fig. (3). The tube is modeled using steel, yield strength, $\sigma_{\mathrm{y}}=$ $430 \mathrm{MPa}$, Density, $\rho=7.85 \times 10^{-6} \mathrm{~kg} / \mathrm{mm}^{3}$, Poisson ratio, $\mathrm{v}=$ 0.3 and Young's modulus, $\mathrm{E}=210 \mathrm{GPa}$.

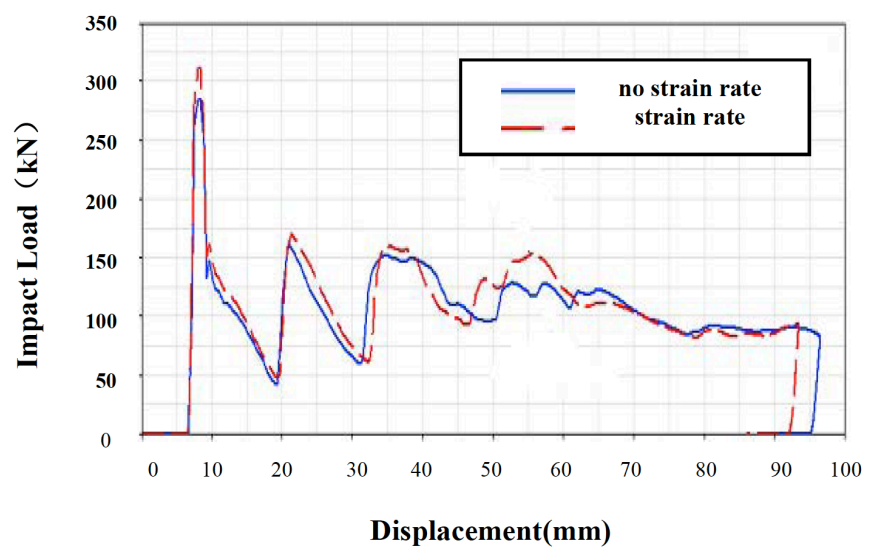

Fig. (4). Impact load - displacement curve of crash-box,

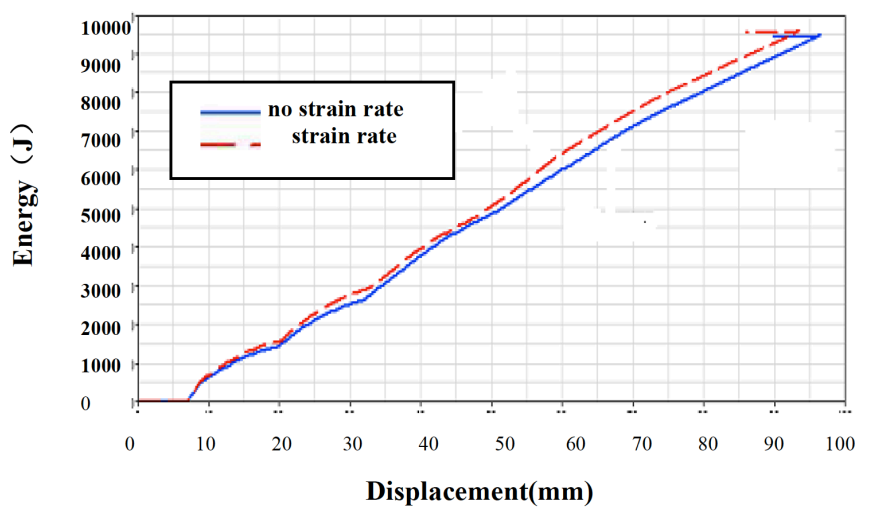

Fig. (5). Energy- displacement curve of crash-box.

The curve of impact load $v s$ displacement is shown in Fig. (4). The curve of energy $v s$ displacement is shown in Fig. (5). The curve of energy $v s$ time is shown in Fig. (6). Table 1 provides a comparison of the main parameters (peak values of impact load for tubes and displacement) obtained by no strain rate and strain rate.

Comparing the simulation results, the energy of the impact is absorbed almost completely for the two conditions, the energy absorption considering strain rate is better than 
not considering the effect of strain rate. But the energy absorbing distance of considering strain rate model is less than that not considering strain rate model, the energy absorption considering strain rate is better than not considering the effect of strain rate.

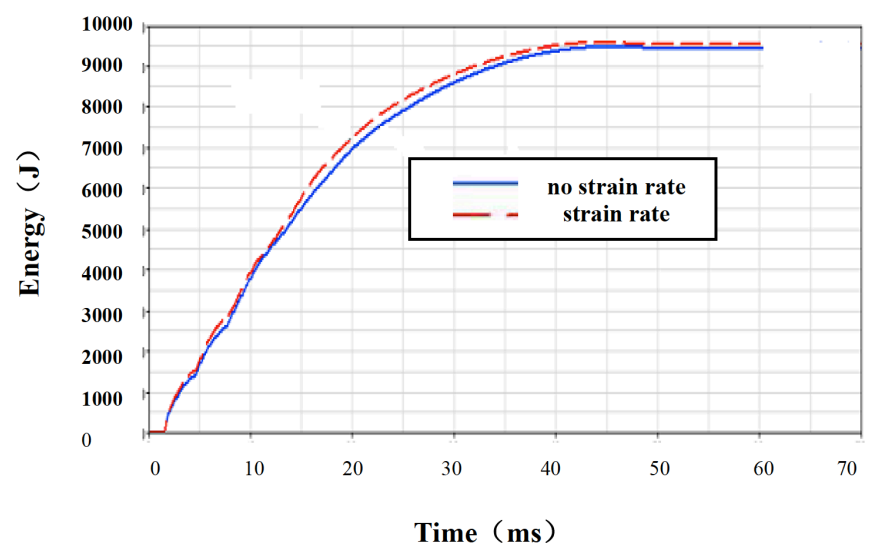

Fig. (6). Energy- time of crash-box.

Table 1. Comparison of results no strain rate and strain rate.

\begin{tabular}{|c|c|c|}
\hline & Pean Impact Load (kN) & Displacement (mm) \\
\hline \hline No strain rate & 288.00 & 97 \\
\hline Strain rate & 311.00 & 93 \\
\hline
\end{tabular}

\subsection{Material Yield strength}

The tube was modeled using steel, in this paper, Density, $\rho=7.85 \times 10-6 \mathrm{~kg} / \mathrm{mm}^{3}$, Poisson ratio, $\mathrm{v}=0.3$ and Young's modulus, $\mathrm{E}=210 \mathrm{GPa}$. yield strength, $\sigma_{\mathrm{y}}=430 \mathrm{MPa}$ and $\sigma_{\mathrm{y}}=$ $516 \mathrm{MPa}$, on the square cross section tubes were adopted as shown in Fig. (3). FE simulation results are shown in Fig. (7). The peak values of impact load for tubes are shown in Table 2.

Results showed that the energy absorption characters of thin-walled tube of square cross section had been increased greatly when yield strength raised. Where the peak value of impact load was $370.1 \mathrm{kN}$, increased about $19 \%$ compared with $\sigma y=450 \mathrm{MPa}$, and displacement was $73.25 \mathrm{~mm}$, decreased about $27.2 \%$ compared with $\sigma_{\mathrm{y}}=450 \mathrm{MPa}$.

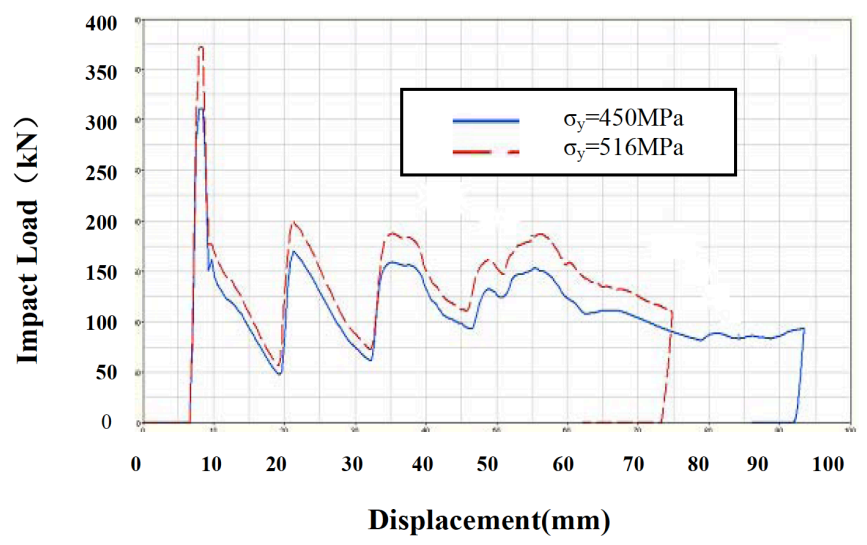

Fig. (7). Impact load $v s$ time curve of crash-box.
Table 2. Comparison of results energy absorbing characteristics.

\begin{tabular}{|c|c|c|}
\hline & Peak Impact Load $(\mathbf{k N})$ & Displacement $(\mathbf{m m})$ \\
\hline \hline$\sigma \mathbf{y}=\mathbf{4 5 0 M P a}$ & 311.00 & 93 \\
\hline$\sigma \mathbf{y}=\mathbf{5 1 6} \mathrm{MPa}$ & 370.1 & 73.25 \\
\hline
\end{tabular}

\subsection{Material Type}

There are many types of metal materials, steel is the common type of automobile crash-box, which is used in a wide variety of impact loading applications, since it is relatively cheap, versatile and efficient for absorbing energy. With the rapid development of automobile industry, the lightweight materials have been applied in the automobile. Aluminum alloy material through the extrusion forming is subjected to the extensive concern [8].

In this paper, the tube is modeled using steel( Density, $\rho$ $=7.85 \times 10-6 \mathrm{~kg} / \mathrm{mm}^{3}$, Poisson ratio, $\mathrm{v}=0.3$ and Young' $\mathrm{s}$ modulus, $\mathrm{E}=210 \mathrm{GPa}$.yield strength, $\sigma_{\mathrm{y}}=430 \mathrm{MPa}$ ) and aluminum alloy (Density, $\rho=2.81 \times 10^{-6} \mathrm{~kg} / \mathrm{mm}^{3}$, Poisson ratio, $\mathrm{v}=0.33$ and Young' $\mathrm{s}$ modulus, $\mathrm{E}=71 \mathrm{GPa}$.yield strength, $\left.\sigma_{\mathrm{y}}=455 \mathrm{MPa}\right)$. On the square cross section tubes were adopted as shown in Fig. (3). Comparison results of collision aluminum alloy and carbon steel crash-box are shown in Figs. $(\mathbf{8}, \mathbf{9})$.

The peak values of impact load for tubes with different material are shown in Table 3. Results showed that all the energy was almost absorbed by two materials, because the energy curve finally turned to a horizontal line. The peak impact of tubes is fundamentally different when different material is adopted. The peak impact of aluminum alloy tubes decreased $37.34 \mathrm{kN}$ compared with steel, and displacement increased $20 \mathrm{~mm}$ compare with steel.

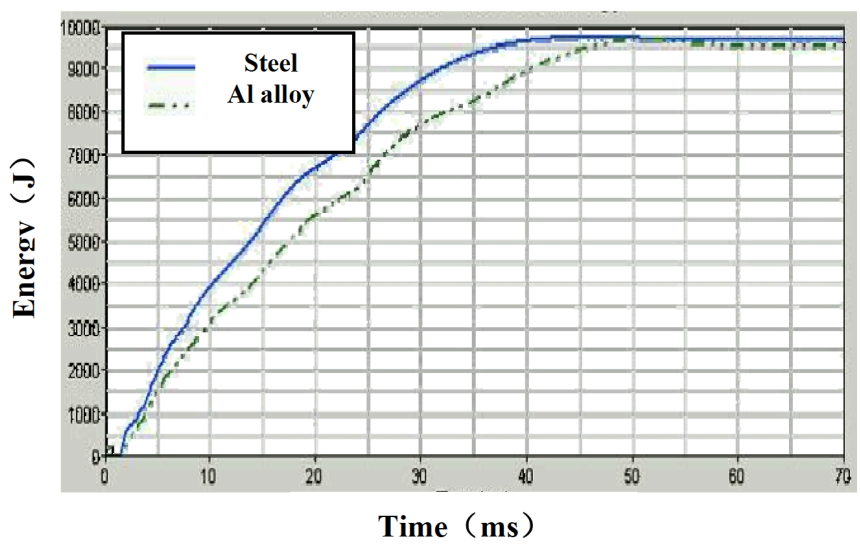

Fig. (8). Energy curve of the tube for the two kind of materials.

\section{CONCLUSION}

The automobile low velocity impact is a very complex mechanical problem, and theory analytical solution is quite difficult. So computer simulation is an effective method. Through study models of material parameters, material properties on automobile energy -absorbing components 
crashworthiness have very important influence. Suitable results of the design are obtained by change material parameters. Material strain rate, material yield strength and material type have certain effect to crashworthiness of energy-absorbing component.

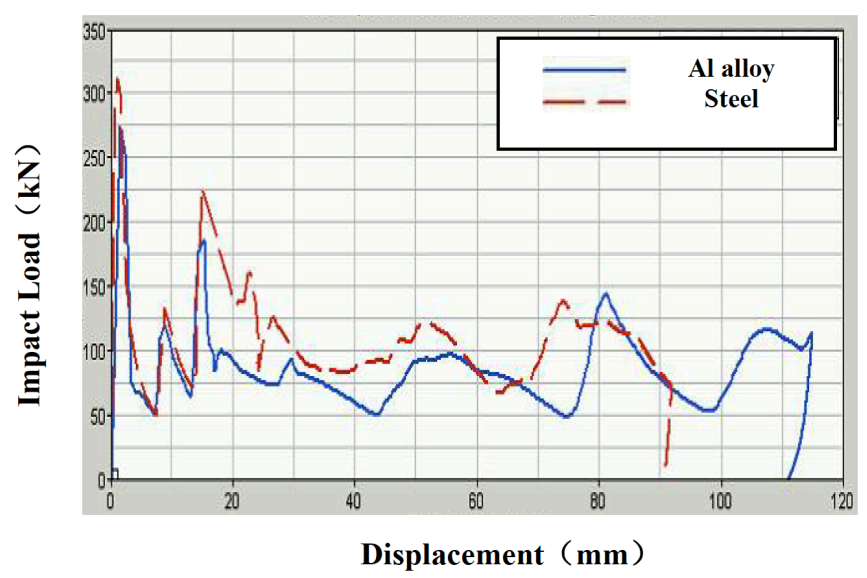

Fig. (9). Impact load $v s$ displacement curve of the tube.

Table 3. Comparison of results energy absorbing characteristics.

\begin{tabular}{|c|c|c|}
\hline & Peak Impact Load (kN) & Displacement (mm) \\
\hline \hline Carbon sheet & 311.00 & 93 \\
\hline Aluminum alloy & 273.66 & 113 \\
\hline
\end{tabular}

\section{ACKNOWLEDGEMENTS}

This work was financially supported by the Heilongjiang Education Committee Science and Technology Project (12531708), and by the National Natural Science Foundation of China (No.41071049).

\section{REFERENCES}

[1] Q. F. Li, Y. J. Liu, H. D. Wang, and S. Y. Yan, "Finite element analysis and shape optimization of automotive crash-box subjected to low velocity impact", International Conference on Measuring Technology and Mechatronics Automation, pp. 791-794, 2009

[2] M. Langseth, O.S. Hopperstad, and A.G. Hanssen, "Crash behaviour of thin-walled aluminium members", Thin-Walled Structures, vol. 32, no.1, pp. 127-150, 1998.

[3] A. Reye, M. Langseth, and O.S. Hopperstad, "Crashworthiness of aluminum extrusions subjected to oblique loading: experiments and numerical analyses", International Journal of Mechanical Sciences, vol. 44, no.4, pp.1965-1984, 2002.

[4] H.R. Zarei, and M. Kröger, "Multiobjective crashworthiness optimization of circular aluminum tubes", Thin-walled Structures, vol. 46, no.1, pp. 301-308, 2006

[5] X. Y. Zhang, X. L. Jin, Y. Y. Li, and G. G. Li, "Improvement design of the main Energy-absorbing automotive parts based on traffic accident analysis", Material \& Design, vol. 29, no. 3, pp. 403-410, 2008.

[6] X. Y. Zhang, X. L. Jin, W. G. Qi and J. Shen, "Analysis and reconstruction of the typical Traffic Accident based on the tire marks", Journal of Basic Science and Engineering, vol. 14, no.3, pp. 418-426, 2006.

[7] G. M. Nagel, and D. P. Thambiratnam, "Computer simulation and energy absorption of tapered thin-walled rectangular tubes", Thinwalled structures, vol. 43, no. 8, pp. 1225-1242, 2005.

[8] G. M. Nagel, and D.P. Thambiratnam, "Dynamic simulation and energy absorption of tapered thin-walled tubes under oblique impact loading", International Journal of Impact Engineering, vol. 32 , no. 10 , pp. $1595-1629,2006$.

\section{CONFLICT OF INTEREST}

The authors confirm that this article content has no conflict of interest.

This is an open access article licensed under the terms of the Creative Commons Attribution Non-Commercial License (http://creativecommons.org/licenses/ by-nc/3.0/) which permits unrestricted, non-commercial use, distribution and reproduction in any medium, provided the work is properly cited. 